This is the final peer-reviewed accepted manuscript of: Roberti, Roberta; Di Francesco, Alessandra; Innocenti, Gloria; Mari, Marta, Potential for biocontrol of Pleurotus ostreatus green mould disease by Aureobasidium pullulans De Bary (Arnaud), which has been published in final form in BIOLOGICAL CONTROL Volume 135, August 2019, Pages 9-15. The final published version is available online at: http://dx.doi.org/10.1016/j.biocontrol.2019.04.016

\title{
Potential for biocontrol of Pleurotus ostreatus green mould disease by Aureobasidium pullulans De Bary (Arnaud)
}

\author{
Roberta Roberti *, Alessandra Di Francesco, Gloria Innocenti , Marta Mari \\ Department of Agricultural and Food Sciences, Alma Mater Studiorum, University of Bologna, Viale G. Fanin, 40, Bologna, Italy
}

\section{A R T I C L E I N F O}

\section{Keywords:}

Oyster mushroom

Aureobasidium pullulans

Trichoderma pleuroti

Trichoderma pleuroticola

Biocontrol

\begin{abstract}
A B S T R A C T
Pleurotus ostreatus, commonly known as "oyster mushroom", is an edible fungus economically important worldwide. The green mould, caused by Trichoderma pleuroti and T. pleuroticola, is a very important fungal disease, and it is commonly controlled by the use of fungicides. The yeast-like fungus Aureobasidium pullulans is a biocontrol agent naturally found throughout a wide range of habitats. The effect of A. pullulans L1 and L8 strains on $P$. ostreatus, T. pleuroti and T. pleuroticola was studied in in vitro assays. Both yeast strains resulted compatible with $P$. ostreatus growth, and effective in reducing the T. pleuroticola and T. pleuroti colony growth. The inhibitory effect of L1 and L8 was similar in the majority of the Trichoderma-A. pullulans combinations on agar plates. Both strains were more efficient than Trichoderma in substrate colonization, and produced volatile and nonvolatile metabolites which reduced Trichoderma growth. When the activity of L1 and L8 was tested against the green mould disease of $P$. ostreatus under controlled conditions similar to those of a mushroom farm, only L8 was effective in controlling the disease. It showed an effect similar to that of the fungicide prochloraz against T. pleuroticola, the less aggressive pathogen, and lower than that of the fungicide against T. pleuroti, the most aggressive. The antagonism was the result of mechanisms like antibiosis and competition for space and nutrients, whereas the direct attachment of $A$. pullulans with hyphae of the pathogens did not play a role.
\end{abstract}

\section{Introduction}

Pleurotus ostreatus (Jacq.) Kümm., commonly known as "oyster mushroom", is an edible basidiomycete fungus economically important worldwide. It is susceptible to a wide range of biotic diseases, and green mould is one of the most important fungal diseases (Sharma and Vijay, 1996; Woo et al., 2004, 2009; Kredics et al., 2006; Park et al., 2006; Hatvani et al., 2007; 2012; Alfonzo et al., 2008; Sobieralski et al., 2012; Innocenti et al., 2019) which is caused by Trichoderma pleuroti S. H. Yu and M.S. Park (2006; previously T. pleurotum) and T. pleuroticola S. H. Yu and M. S. Park (2006) (Hatvani et al., 2007; Komon-Zelazowska et al., 2007; Innocenti et al., 2019). Typical symptoms of the disease are green sporulation areas on the surface of cultivation substrate that is exposed to the green mould infection mostly during the spawn run phase.

The disease control is commonly based on fungicide application, and currently only prochloraz is allowed for use in mushroom farms in Italy (Sponix Flow, Adama Makhteshim Chemical Works Ltd, Beer-Sheva, Israel, Reg. n. 13671 16/03/2007, modified 19/06/2017, art.
7(1), D.P.R. n. 55/2012). However, in accordance with the aims of the European Regulation EC $1107 / 2009$, concerning the placing of plant protection products on the market and repealing Council Directives 79/ 117/EEC and 91/414/EEC, priority should be given to non-chemical and natural alternatives wherever possible. Considering also the consumer demand of healthy foods obtained with cultivation system with low environmental impact, products based on antagonistic microorganisms could be useful tools. Bacillus amyloliquefaciens, B. subtilis and B. licheniformis isolates seemed to be appropriate to be developed as biocontrol products to overcome the Trichoderma green mould problem of P. ostreatus (Nagy et al., 2012; Mwangi et al., 2017). A product based on B. amyloliquefaciens D747 strain (Amylo- $\mathrm{X}^{\circledR}$, Biogard, CBC (Europe) S.r.l., Nova Milanese, MB, Italy) is commercialized in Italy only against T. aggressivum which is responsible of Agaricus bisporus green mould.

Aureobasidium pullulans (De Bary) Arnaud is a yeast-like fungus, naturally found throughout a wide range of terrestrial and aquatic habitats under temperate, tropical and artic environment (Samson et al., 2004; Gunde-Cimerman et al., 2000; Zalar et al., 2008), and able to live under controlled atmosphere gases (Martínez-Romero et al., 2012). Aureobasidium pullulans is well known for its biotechnological significance

\footnotetext{
* Corresponding author.

Email address: roberta.roberti@unibo.it (R. Roberti)
} 
as a producer of the biodegradable extracellular polysaccharide pullulan, and of a variety of the hydrolytic enzymes (Zalar et al., 2008). It naturally occurs as endophyte (Pugh and Buckley, 1971; Martini et al., 2009; Parsa et al., 2016) or epiphyte (Andrews, 2006) of a wide range of plant species and tissues. Aureobasidium pullulans showed biocontrol activity against postharvest diseases such as nectarine brown rot (Janisiewicz et al., 2010; Mari et al., 2012), kiwifruit grey mould (Di Francesco et al., 2018b), and strawberry rot (Lima et al., 1997). It was effective also against field diseases such as vineyard sour rot (Dimakopoulou et al., 2008), tomato late blight (Di Francesco et al., 2017), and winter wheat stem base diseases (Wachowska and Borowska, 2014). Mechanisms involved in its biocontrol activity are competition for nutrients, antibiosis, parasitism, and induction of plant resistance (Ippolito et al., 2000; Bencheqroun et al., 2007; Zhang et al., 2010; Di Francesco et al., 2015b, 2017). To our knowledge, no studies have been carried out on A. pullulans potential for the biological control of $P$. ostreatus green mould disease.

The aim of this study was to evaluate: (i) the compatibility of A.pullulans with $P$. ostreatus growth in in vitro assays; (ii) the effect of $A$. pullulans against T. pleuroti and T. pleuroticola growth in in vitro assays; (iii) the potential biocontrol effect against green mould disease caused by Trichoderma under controlled conditions similar to those of a mushroom farm.

\section{Materials and methods}

\subsection{Aureobasidium pullulans, Trichoderma spp. and Pleurotus ostreatus}

In all experiments A. pullulans L1 and L8 strains were used. They were isolated from "Red haven" peach carposphere harvested in the experimental orchard of Bologna University located in Cadriano, Bologna, Italy (Mari et al., 2012). They were molecularly identified (Di Francesco et al., 2018a) and maintained on nutrient yeast dextrose agar (NYDA, $8 \mathrm{gL}^{-1}$ nutrient broth, $5 \mathrm{gL}^{-1}$ yeast extract, $10 \mathrm{gL}^{-1}$ dextrose, $25 \mathrm{gL}^{-1}$ technical agar (Oxoid, UK), at $4^{\circ} \mathrm{C}$ in the dark, in the culture collection of CRIOF - Department of Agricultural and Food Sciences (Distal), University of Bologna. For the experiments, they were transferred on NYDA plates and incubated at $25^{\circ} \mathrm{C}$ for two days in the dark. Yeast cell suspensions were then obtained by adding distilled sterile water containing $0.05 \%(\mathrm{v} / \mathrm{v}$ ) Tween 80 , and by scraping the colony surface with a sterile loop. The final concentration used in all experiments was $10^{8}$ cells $\mathrm{mL}^{-1}$.

Trichoderma pleuroticola AFS 432 (Tpa 432) and AFS 488 (Tpa 488), and T. pleuroti AFS 492 (Tpi 492) and AFS 497 (Tpi 497) strains were used. They were isolated from green mould-affected samples of wheat straw substrate of $P$. ostreatus from a mushroom farm located in Emilia Romagna, Italy. They were molecularly identified by amplification of the tef1 gene fragment (Innocenti et al., 2019), and maintained in potato dextrose broth (PDB, Difco) added with $15 \%$ glycerol at $-80^{\circ} \mathrm{C}$, in the culture collection of Distal, University of Bologna, under AFS codes.

The commercial P. ostreatus strains 'Spoppo' (PoSp; Sylvan, Somycel, Langeais, France) and K12 (Micelio Fungisem S.A., La Rioja, Spain), widely cultivated in Italian mushroom farms, were utilised. The spawn consisted in sterile millet seeds colonised by the mycelium.

\subsection{Effect of Aureobasidium pullulans on Pleurotus ostreatus and Trichoderma colony growth}

The effect of A. pullulans L1 and L8 strains on the mycelial growth of PoSp and K12, Tpa 432 and 488, and Tpi 492 and 497 was investigated by the following assays: (i) dual culture; (ii) volatile organic compounds (VOCs); (iii) nonvolatile organic compounds (NVOCs). The mycelium of $P$. ostreatus PoSp and K12 was obtained by plating millet kernels of commercial spawns on Potato Dextrose Agar (PDA, $39 \mathrm{gL}^{-1}$, Oxoid, UK) for 7 days at $20^{\circ} \mathrm{C}$ in the dark.

In the dual culture assay, each $P$. ostreatus or Trichoderma strain was separately co-cultured with each yeast strain on PDA plates. In each plate, a mycelial plug ( $6 \mathrm{~mm}$ in diam.) from 7 day-old colony of $P$. ostreatus or Trichoderma was inoculated at $30-\mathrm{mm}$ distance from the plate edge. Aureobasidium pullulans inoculum $\left(100 \mu \mathrm{L}, 10^{8}\right.$ cells $\left.\mathrm{mL}^{-1}\right)$ from $48 \mathrm{~h}$-old colony on NYDA was streaked by a sterile loop $30 \mathrm{~mm}$ from the plug (Di Francesco et al., 2017). In control plates, only P. ostreatus or Trichoderma plugs were inoculated. Plates were incubated at $25^{\circ} \mathrm{C}$, in the dark for 3 days, then the radius of fungal colony was measured on a line from the centre of the plug to yeast colony.

For the VOC assay, the technique of Dennis and Webster (1971a) was used. Aureobasidium pullulans was inoculated by spreading $100 \mu \mathrm{L}$ of suspension, $10^{8}$ cells $\mathrm{mL}^{-1}$ (Di Francesco et al., 2015b) in each NYDA plate. After 48 -h incubation at $25^{\circ} \mathrm{C}$, the lid of the plate was replaced by a bottom PDA plate inoculated with $6 \mathrm{~mm}$ P. ostreatus or Trichoderma mycelial plug, then the two bottoms were tapped together with a double layer of Parafilm. In the control plates, PDA bottoms not inoculated with yeast strains were tapped together with $P$. ostreatus or Trichoderma bottoms. The diameter of Trichoderma or P. ostreatus colony was measured after $25^{\circ} \mathrm{C}$ incubation in the dark respectively for 3 or 7 days.

For the NVOC assay, the technique of Dennis and Webster (1971b) was used. A cell suspension $(100 \mu \mathrm{L})$ of each A. pullulans strain obtained from $48 \mathrm{~h}$-old colonies on NYDA, was spread on a sterile cellophane layer PTT (Safta, PC, Italy) positioned on a $20 \mathrm{~mL}$ NYDA plate. In control plates, $100 \mu \mathrm{L}$ of sterile water was spread on the cellophane. After 48-h incubation at $25^{\circ} \mathrm{C}$, the cellophane was removed, and a mycelial plug ( $6 \mathrm{~mm}$ diam.) of each $P$. ostreatus or Trichoderma was inoculated in the centrum. The diameter of Trichoderma or P. ostreatus colony was measured after $25^{\circ} \mathrm{C}$ incubation in the dark respectively for 3 or 7 days.

In all experiments, three plates (replicates) were used for each combination and for the controls.

\subsection{In vivo assay}

The $P$. ostreatus growing substrate was prepared by using the following technique similar to that used in mushroom farm. Chopped wheat straw $\left(2-5 \mathrm{~cm}\right.$ ) was steam pasteurised at $90^{\circ} \mathrm{C}$ for $1 \mathrm{~h}$ (Sobieralski et al., 2012) and added to PoSp spawn (2\% v/w). An amount of $100 \mathrm{~g}$ of substrate + PoSp was then distributed in each perforated transparent plastic food container $(15 \times 8 \times 10 \mathrm{~cm})$. The substrate was treated with $20 \mathrm{~mL}$ of $A$. pullulans $\mathrm{L} 1$ or L8 $\left(2.4 \times 10^{7}\right.$ cells/g substrate) suspension separately, or with prochloraz (Sponix Flow, $450 \mathrm{gL}^{-1}$, Adama Makhteshim LTD, Beer-Sheva, Israel) at $1.25 \mu \mathrm{LL}^{-1}$ dose (field dose) as chemical control. Trichoderma inoculum was obtained from abundantly sporulating colonies on PDA plates maintained at $25^{\circ} \mathrm{C}$ for 4 days in the dark, then under natural light. A $3 \mathrm{~mL}$ Tpa 432 or Tpi 492 water spore suspension was separately inoculated in the substrate $\left(5 \times 10^{3}\right.$ spore/g substrate) immediately after yeast or prochloraz treatment.

Each container was then wrapped in a plastic bag closed by a cotton plug. Controls consisted in containers with PoSp + water $(23 \mathrm{~mL})$, PoSp + Trichoderma $(3 \mathrm{~mL})+$ water $(20 \mathrm{~mL})$, PoSp + L1 $(20 \mathrm{~mL})+$ water $(3 \mathrm{~mL})$ and PoSp $+\mathrm{L} 8(20 \mathrm{~mL})+$ water $(3 \mathrm{~mL})$. The treatment prochloraz + L8 was not considered, because in a preliminary in vitro assay, prochloraz completely inhibited the yeast colony growth. The time and the dose of prochloraz treatment were comparable to those used in mushroom farms, where the fungicide is applied to substrate once at spawn. Six replicates were performed for each treatment for a total of 54 containers that were located in a growth chamber following a complete randomized design at $23-25^{\circ} \mathrm{C}$ and at $80 \%$ 
relative humidity. Four weeks later, during the spawn run phase, the colonisation of substrate by Trichoderma was visually assessed for each container using a six-point scale where: 0 , no colonisation; 1 , sporadic growth few small green areas; 2, growth (colonization) less than $20 \%$ of substrate colonized by green mould; $3,20-50 \%$ of colonized substrate; $4,51-70 \%$ of colonized substrate and 5 , more than $70 \%$ colonisation by green mould (Innocenti et al., 2019, modified). The colonization index for each treatment and control was then calculated as the mean of the values of the replicates. The efficacy of green mould disease control was calculated with the following formula: ((Ic - It)/Ic) $\times 100$, where Ic is the colonization index in the control and It is the colonization index in the treatment. At the end of the experiment, A. pullulans was randomly re-isolated from the substrate and identified as described by Di Francesco et al. (2018a).

All in vitro and in vivo experiments were conducted twice with similar results. The data of both experiments are reported.

\subsection{Statistical analysis}

Data were subjected to two-way ANOVA. Separation of means, when possible, was performed using the Student Newman Keuls test. Data were reported as mean values \pm standard deviation (SD). Analyses were performed with the software Statgraphic Plus Version 2.1 (Statistical Graphics Corp., USA 1996).

\section{Results}

\subsection{Effect of Aureobasidium pullulans on Pleurotus ostreatus colony growth}

The co-culturing of A. pullulans L1 and L8 and PoSp and K12 showed that the colony growth of both strains of $P$. ostreatus were not influenced by yeast strains. Indeed two-way ANOVA analysis showed the following values for what concerns the experiment $1, A$. pullulans strain factor, $\mathrm{F}=0.09$ and $P=0.92$, for $P$. ostreatus strain factor, $\mathrm{F}=1.25$ and $P=0.29$, and for interaction between the two factors, $\mathrm{F}=0.87$ and $P=0.44$. For what concern the experiment 2, values are the following: A. pullulans strain factor, $\mathrm{F}=1.53$ and $P=0.26$, for $P$. ostreatus strain factor, $\mathrm{F}=0.25$ and $P=0.62$, and for interaction between the two factors, $\mathrm{F}=0.07$ and $P=0.93$.

The effect of L1 and L8 VOCs on PoSp and K12 colony growth is reported in Table 1 . In both experiments, A. pullulans L8 significantly increased the mean value of both $P$. ostreatus strains colony diameter in comparison to the mean of untreated controls. The effect of L1 treat-

Table 1

Effect of volatile organic compounds produced by Aureobasidium pullulans L1 and L8 strains on colony diameter of Pleurotus ostreatus 'Spoppo' and 'K12' strains, 7 days after inoculation.

\begin{tabular}{llll}
\hline Treatment & P. ostreatus diameter $(\mathrm{mm})$ & Mean \\
\hline & $\mathrm{K} 12$ & PoSp & \\
\hline Experiment 1 & & & \\
A. pullulans L1 & $68.7 \pm 1.2$ & $57.0 \pm 4.6$ & $62.8 \pm 7.1 \mathrm{a}$ \\
A. pullulans L8 & $84.0 \pm 5.3$ & $65.7 \pm 4.5$ & $74.8 \pm 11.0 \mathrm{~b}$ \\
Untreated & $64.3 \pm 5.1$ & $58.7 \pm 4.9$ & $61.5 \pm 5.6 \mathrm{a}$ \\
Mean & $70.3 \pm 9.7 \mathrm{~B}$ & $60.4 \pm 5.7 \mathrm{~A}$ & \\
Experiment 2 & & & \\
A. pullulans L1 & $67.0 \pm 1.7$ & $56.0 \pm 4.0$ & $61.5 \pm 6.6 \mathrm{a}$ \\
A. pullulans L8 & $86.0 \pm 5.2$ & $66.3 \pm 4.2$ & $76.2 \pm 11.6 \mathrm{~b}$ \\
Untreated & $64.7 \pm 4.5$ & $56.7 \pm 6.1$ & $60.7 \pm 6.5 \mathrm{a}$ \\
Mean & $72.6 \pm 10.7 \mathrm{~B}$ & $59.7 \pm 6.5 \mathrm{~A}$ & \\
\hline
\end{tabular}

In both experiments, treatment and $P$. ostreatus strain factors are significant and their interaction is not significant, according to two-way ANOVA $(P<0.05)$. Mean values \pm SD followed by the same upper case letter in a line, and by the same lower case letter in a column are not significantly different according to SNK test $(P<0.01)$. ment was not different from that of untreated control. The mean diameter of $P$. ostreatus K12 colonies was significantly higher than that of PoSP independently from treatment.

The effect of L1 and L8 NVOCs on PoSp and K12 colony growth is reported in Table 2. In both experiments, the mean colony diameter of $P$. ostreatus strains was significantly increased by A. pullulans L8 in comparison to control means. Pleurotus ostreatus colony treated with the strain L1 showed a similar growth of untreated control. The mean diameter of P. ostreatus K12 colony was significantly higher than that of PoSP.

\subsection{Effect of Aureobasidium pullulans on Trichoderma colony growth}

The co-culturing of A. pullulans and Trichoderma strains showed that the colony growth of all Trichoderma strains were influenced by yeast strains (Table 3). In both experiments, the colony growth of Tpi 492 and Tpi 497 was reduced by L1 and L8, and no significant differences were observed between the two A. pullulans strains. Both yeast strains reduced more Tpi 492 colony growth than that of Tpi 497. The untreated control Tpi 492 showed a lower growth than that of Tpi 497.

Table 2

Effect of nonvolatile organic compounds produced by Aureobasidium pullulans L1 and L8 strains on colony diameter of Pleurotus ostreatus 'Spoppo' and 'K12' strains 7 days after inoculation.

\begin{tabular}{llll}
\hline Treatment & \multicolumn{2}{l}{ P. ostreatus diameter $(\mathrm{mm})$} & Mean \\
\hline & $\mathrm{K} 12$ & PoSp & \\
\hline Experiment 1 & & & \\
A. pullulans L1 & $64.0 \pm 4.6$ & $54.3 \pm 5.5$ & $59.2 \pm 7.0 \mathrm{a}$ \\
A. pullulans L8 & $71.0 \pm 1.0$ & $60.0 \pm 1.0$ & $65.5 \pm 6.1 \mathrm{~b}$ \\
Untreated & $62.0 \pm 3.0$ & $54.1 \pm 3.6$ & $59.0 \pm 6.2 \mathrm{a}$ \\
Mean & $66.3 \pm 4.5 \mathrm{~B}$ & $56.1 \pm 4.4 \mathrm{~A}$ & \\
Experiment 2 & & & \\
A. pullulans L1 & $65.3 \pm 4.5$ & $54.0 \pm 7.0$ & $59.7 \pm 8.1 \mathrm{a}$ \\
A. pullulans L8 & $72.7 \pm 2.5$ & $61.0 \pm 2.0$ & $66.8 \pm 6.7 \mathrm{~b}$ \\
Untreated & $64.0 \pm 3.0$ & $56.3 \pm 2.5$ & $60.2 \pm 4.9 \mathrm{a}$ \\
Mean & $67.3 \pm 5.0 \mathrm{~B}$ & $57.1 \pm 4.9 \mathrm{~A}$ & \\
\hline
\end{tabular}

In both experiments, treatment and $P$. ostreatus strain factors are significant and their interaction is not significant, according to two-way ANOVA $(P<0.05)$. Mean values \pm SD followed by the same upper case letter in a line, and by the same lower case letter in a column are not significantly different according to SNK test $(P<0.01)$.

Table 3

Effect of Aureobasidium pullulans L1 and L8 strains on colony growth (mm) of Trichoderma pleuroti AFS 492 and AFS 497, and T. pleuroticola AFS 432 and AFS 488 after 3 days of incubation on PDA plates in co-culturing conditions.

\begin{tabular}{lllll}
\hline Treatment & T. pleuroti & \multicolumn{3}{l}{ T. pleuroticola } \\
\hline & AFS 492 & AFS 497 & AFS 432 & AFS 488 \\
\hline Experiment 1 & & & & \\
A. pullulans & $16.7 \pm 2.1$ & $20.0 \pm 0.0$ & $20.7 \pm 1.2$ & $19.7 \pm 1.5 \mathrm{aA}$ \\
L1 & $\mathrm{aA}$ & $\mathrm{aB}$ & $\mathrm{bA}$ & \\
A. pullulans & $15.8 \pm 4.0$ & $20.8 \pm 1.3$ & $15.7 \pm 0.8$ & $20.0 \pm 1.0 \mathrm{aB}$ \\
L8 & $\mathrm{aA}$ & $\mathrm{aB}$ & $\mathrm{aA}$ & \\
Untreated & $20.3 \pm 2.1$ & $33.0 \pm 1.0$ & $30.0 \pm 0.0$ & $34.0 \pm 1.0 \mathrm{bB}$ \\
& $\mathrm{bA}$ & $\mathrm{bB}$ & $\mathrm{cA}$ & \\
Experiment 2 & & & & \\
A. pullulans & $15.7 \pm 0.6$ & $21.0 \pm 1.0$ & $21.3 \pm 1.5$ & $20.3 \pm 2.1 \mathrm{aA}$ \\
L1 & $\mathrm{aA}$ & $\mathrm{aB}$ & $\mathrm{aA}$ & \\
A. pullulans & $16.4 \pm 2.0$ & $21.4 \pm 1.9$ & $19.7 \pm 0.6$ & $22.7 \pm 1.0 \mathrm{aB}$ \\
L8 & $\mathrm{aA}$ & $\mathrm{aB}$ & $\mathrm{aA}$ & \\
Untreated & $21.3 \pm 2.1$ & $30.3 \pm 1.5$ & $31.0 \pm 1.0$ & $35.3 \pm 1.5 \mathrm{bB}$ \\
& $\mathrm{bA}$ & $\mathrm{bB}$ & $\mathrm{bA}$ & \\
\hline
\end{tabular}

In both experiments, Trichoderma species, Trichoderma strain, and treatment (L1 and L8) factors and their interaction are significant according to two-way ANOVA $(P<0.05)$. Mean values \pm SD followed by the same upper case letter in a line and by the same lower case letter in a column are not significantly different according to SNK test $(P<0.01)$. 
In both experiments, L1 and L8 strains significantly reduced the colony growth of Tpa 432 and Tpa 488 compared to untreated controls. In experiment $1, A$. pullulans L8 reduced Tpa 432 colony growth more than L1, and in experiment 2, no difference was found between the two yeast strains. In both experiments, L1 and L8 strains showed a similar effect in reducing Tpa 488 colony growth. The L8 strain reduced Tpa 432 colony growth more than Tpa 488 in both experiments. The untreated control Tpa 432 showed a lower growth than that of Tpa 488.

For what concerns the effect of L1 and L8 VOCs on Tpi 492 and Tpi 497 colony growth (Table 4), two-way ANOVA indicated that, in the experiment 1 , there was no significant interaction between treatment and Trichoderma strain factors, then a comparison was made among the mean values of each factor. Both L1 and L8 yeast strains similarly reduced Trichoderma colony growth with respect to untreated control. Mean value of Tpi 492 growth was significantly lower than that of Tpi 497. In experiment 2 , there was significant interaction between treatment and Trichoderma strain factors. L1 and L8 VOCs significantly and similarly reduced Tpi 492 and Tpi 497 colony growth with respect to untreated control. Both yeast strains reduced Tpi 492 colony growth more than that of Tpi 497. For what concerns T. pleuroticola, in both experiments L1 and L8 strains significantly reduced Tpa 432 and Tpa 488 colony growth compared to untreated controls, and similarly reduced the colony growth of Tpa 432 strain. In the experiment 2, L8 strain reduced Tpa 488 colony growth more than L1. Both yeast strains reduced the Tpa 432 colony growth more than that of Tpa 488.
The effect of NVOCs produced by L1 and L8 on Trichoderma colony growth is reported in Table 5. For what concerns T. pleuroti, in both experiments, L1 and L8 strains significantly reduced the colony growth of Tpi 492 and Tpi 497 compared to the untreated control. In the first experiment, L8 strain reduced Tpi 492 colony growth more than L1. In both experiments, the two A. pullulans strains similarly reduced Tpi 497 colony growth. For what concerns T. pleuroticola, two-way ANOVA indicated no significant interaction between treatment and Trichoderma strains factors, then a comparison was made among the mean values of each factor for both experiments. Aureobasidium pullulans L1 and L8 similarly reduced $T$. pleuroticola colony growth independently of Trichoderma strain. The mean growth of Tpa 488 was similar to that of Tpa 432.

\subsection{In vivo assay}

In this assay, Tpa 432 and Tpi 492 were used, due to the fact that in in vitro experiments they were the most sensitive strains to A.pullulans. No symptoms of green mould disease were observed in uninfected control. The effect of L1 and L8 yeast strains against the green mould disease of $P$. ostreatus 'Spoppo' strain is reported in Table 6. The L8 treatment was significantly effective against Tpi 492 by reducing the substrate colonization index by $18.8 \%$ and by $30 \%$ compared with that of the infected control in experiment 1 and 2, respectively. In both experiments, L1 treatment was not effective against the disease caused by Tpi 492. Prochloraz was the most effective treatment against Tpi 492 disease, it reduced the colonization index of substrate by $62.5 \%$ and by

Table 4

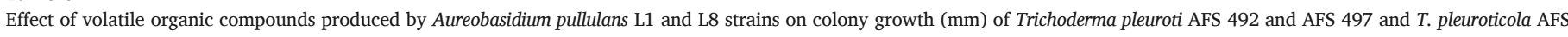
432 and AFS 488 after 3 days of incubation on PDA plates.

\begin{tabular}{|c|c|c|c|c|c|}
\hline \multirow[t]{2}{*}{ Treatment } & \multicolumn{3}{|l|}{ T. pleuroti } & \multicolumn{2}{|l|}{ T. pleuroticola } \\
\hline & AFS 492 & AFS 497 & Mean & AFS 432 & AFS 488 \\
\hline \multicolumn{6}{|l|}{ Experiment 1} \\
\hline A. pullulans L1 & $51.3 \pm 4.2$ & $73.7 \pm 6.5$ & $62.5 \pm 13.2 \mathrm{a}$ & $60.3 \pm 6.8 \mathrm{aA}$ & $72.3 \pm 2.5 \mathrm{aB}$ \\
\hline A. pullulans L8 & $49.3 \pm 4.5$ & $66.3 \pm 3.2$ & $57.8 \pm 9.9 \mathrm{a}$ & $56.3 \pm 5.1 \mathrm{aA}$ & $74.3 \pm 4.0 \mathrm{aB}$ \\
\hline Untreated & $73.3 \pm 2.0$ & $90.0 \pm 0.0$ & $81.7 \pm 9.2 b$ & $90.0 \pm 0.0 \mathrm{bA}$ & $90.0 \pm 0.0 \mathrm{bA}$ \\
\hline Mean & $58.0 \pm 11.9 \mathrm{~A}$ & $76.7 \pm 11.1 \mathrm{~B}$ & & & \\
\hline \multicolumn{6}{|l|}{ Experiment 2} \\
\hline A. pullulans L1 & $55.6 \pm 2.1 \mathrm{aA}$ & $69.0 \pm 1.0 \mathrm{aB}$ & & $49.7 \pm 3.8 \mathrm{aA}$ & $74.7 \pm 5.5 \mathrm{bB}$ \\
\hline A. pullulans L8 & $56.3 \pm 3.2 \mathrm{aA}$ & $64.0 \pm 3.6 \mathrm{aB}$ & & $52.3 \pm 2.1 \mathrm{aA}$ & $65.3 \pm 3.2 \mathrm{aB}$ \\
\hline Untreated & $88.7 \pm 1.0 \mathrm{bA}$ & $87.0 \pm 2.6 \mathrm{bA}$ & & $83.0 \pm 2.6 \mathrm{bA}$ & $88.3 \pm 1.5 \mathrm{cA}$ \\
\hline
\end{tabular}

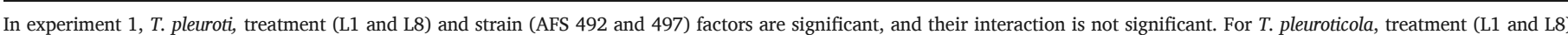

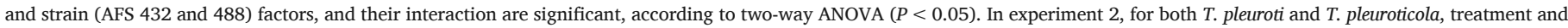

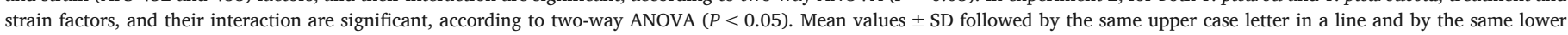
case letter in a column are not significantly different according to SNK test $(P<0.01)$.

Table 5

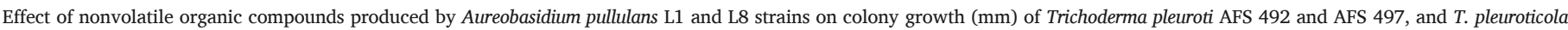
AFS 432 and AFS 488 after 3 days of incubationon PDA plates.

\begin{tabular}{|c|c|c|c|c|c|}
\hline \multirow[t]{2}{*}{ Treatment } & \multicolumn{2}{|l|}{ T. pleuroti } & \multicolumn{3}{|l|}{ T. pleuroticola } \\
\hline & AFS 492 & AFS 497 & AFS 432 & AFS 488 & Mean \\
\hline \multicolumn{6}{|l|}{ Experiment 1} \\
\hline A. pullulans L1 & $35.7 \pm 1.5 \mathrm{bA}$ & $38.6 \pm 1.6 \mathrm{aA}$ & $46.3 \pm 1.5$ & $42.3 \pm 4.0$ & $44.3 \pm 3.5 \mathrm{a}$ \\
\hline A. pullulans L8 & $22.0 \pm 1.0 \mathrm{aA}$ & $37.0 \pm 1.7 \mathrm{aA}$ & $47.7 \pm 2.5$ & $40.7 \pm 1.5$ & $44.2 \pm 4.3 \mathrm{a}$ \\
\hline Untreated & $59.0 \pm 2.6 \mathrm{cA}$ & $66.7 \pm 0.6 \mathrm{bB}$ & $77.7 \pm 0.6$ & $76.3 \pm 0.6$ & $77.0 \pm 0.9 b$ \\
\hline Mean & & & $57.2 \pm 15.4 \mathrm{~A}$ & $53.1 \pm 17.6 \mathrm{~A}$ & \\
\hline \multicolumn{6}{|l|}{ Experiment 2} \\
\hline A. pullulans L1 & $36.3 \pm 2.3 \mathrm{aA}$ & $38.1 \pm 2.6 \mathrm{aA}$ & $45.3 \pm 1.5$ & $41.0 \pm 3.6$ & $43.2 \pm 3.4 \mathrm{a}$ \\
\hline A. pullulans L8 & $32.3 \pm 2.5 \mathrm{aA}$ & $31.7 \pm 3.5 \mathrm{aA}$ & $49.0 \pm 2.6$ & $44.3 \pm 2.1$ & $46.7 \pm 3.3 \mathrm{a}$ \\
\hline Untreated & $62.7 \pm 2.1 \mathrm{bA}$ & $71.7 \pm 1.5 \mathrm{bB}$ & $82.3 \pm 2.5$ & $81.7 \pm 2.5$ & $82.0 \pm 2.3 b$ \\
\hline Mean & & & $58.9 \pm 17.8 \mathrm{~A}$ & $55.7 \pm 19.7 \mathrm{~A}$ & \\
\hline
\end{tabular}

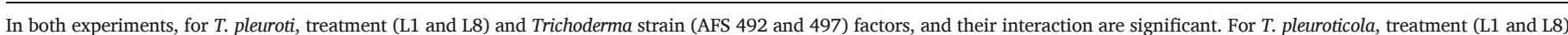

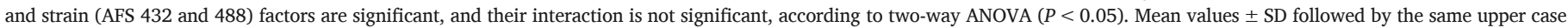
letter in a line and by the same lower case letter in a column are not significantly different according to SNK test $(P<0.01)$. 
Table 6

In vivo assay: effect of Aureobasidium pullulans L1 and L8 strains and prochloraz on substrate colonisation rate by Trichoderma pleuroti AFS 492 and T. pleuroticola AFS 432, 28 days after Pleurotus ostreatus 'Spoppo' strain spawning under growth chamber conditions.

\begin{tabular}{|c|c|c|c|c|}
\hline \multirow[t]{2}{*}{ Treatment $^{\mathrm{a}}$} & \multicolumn{2}{|c|}{$\begin{array}{l}\text { Experiment } 1 \text { - Colonization } \\
\text { index }(0-5)\end{array}$} & \multicolumn{2}{|c|}{$\begin{array}{l}\text { Experiment } 2 \text { - Colonization } \\
\text { index }(0-5)\end{array}$} \\
\hline & $\begin{array}{l}\text { T. pleuroti } \\
\text { AFS } 492\end{array}$ & $\begin{array}{l}\text { T. pleuroticola } \\
\text { AFS } 432\end{array}$ & $\begin{array}{l}\text { T. pleuroti } \\
\text { AFS } 492\end{array}$ & $\begin{array}{l}\text { T. pleuroticola } \\
\text { AFS } 432\end{array}$ \\
\hline $\begin{array}{l}\text { A. pullulans } \\
\text { L1 }\end{array}$ & $\begin{array}{l}4.58 \pm 0.66 \\
\mathrm{cB}\end{array}$ & $\begin{array}{l}1.75 \pm 1.25 \\
\mathrm{bA}\end{array}$ & $\begin{array}{l}4.67 \pm 0.52 \\
\text { cB }\end{array}$ & $\begin{array}{l}2.25 \pm 0.76 \\
\text { bcA }\end{array}$ \\
\hline $\begin{array}{l}\text { A. pullulans } \\
\text { L8 }\end{array}$ & $\begin{array}{l}3.83 \pm 0.41 \\
b B\end{array}$ & $\begin{array}{l}0.92 \pm 0.80 \\
\text { aA }\end{array}$ & $\begin{array}{l}3.50 \pm 0.55 \\
\text { bB }\end{array}$ & $\begin{array}{l}1.25 \pm 0.76 \\
\text { abA }\end{array}$ \\
\hline Prochloraz & $\begin{array}{l}1.75 \pm 0.42 \\
\mathrm{aB}\end{array}$ & $\begin{array}{l}0.50 \pm 0.55 \\
\mathrm{aA}\end{array}$ & $\begin{array}{l}2.17 \pm 0.41 \\
\mathrm{aB}\end{array}$ & $0.67 \pm 0.52 \mathrm{aA}$ \\
\hline $\begin{array}{l}\text { Infected } \\
\text { control }\end{array}$ & $\begin{array}{l}4.67 \pm 0.52 \\
\mathrm{cB}\end{array}$ & $\begin{array}{l}2.67 \pm 0.82 \\
\text { bA }\end{array}$ & $5.0 \pm 0.0 \mathrm{cB}$ & $2.33 \pm 0.52 \mathrm{cA}$ \\
\hline
\end{tabular}

In both experiments, treatment and Trichoderma species factors, and their interaction are significant according to two-way ANOVA $(P<0.05)$. Mean values \pm SD followed by the same upper case letter in a line and by the same lower case letter in a column are not significantly different according to SNK test $(P<0.05)$.

a A. pullulans L1 and L8 concentration, $5 \times 10^{3}$ spore/g substrate; prochloraz dose, $1.25 \mu \mathrm{LL}^{-1}$.

$56.6 \%$ in experiment 1 and 2, respectively. The L8 treatment was effective against Tpa 432 by reducing the colonization index by $65.5 \%$ and by $46.3 \%$, compared with that of infected control in experiment 1 and 2 , respectively. It showed a colonization index value statistically similar to that of prochloraz. The treatment with L1 was not effective. In infected controls, the colonization index value of Tpi 492 was higher than that of Tpa 432.

\section{Discussion}

The green mould caused by Trichoderma pleuroticola and T. pleuroti is one of the most serious diseases of Pleurotus ostreatus that frequently causes dramatic production losses (Hatvani et al., 2007, 2012; Bellettini et al., 2018; Innocenti et al., 2019). Currently, the only tool available to control the disease in $P$. ostreatus Italian farms is the prochloraz application at spawn phase. The cultivation substrate can be treated only at this phase, because it is bagged immediately after. Innocenti et al. (2019) showed that prochloraz was effective against both Trichoderma species responsible for the disease, however they observed that the treatment at the spawn phase was not sufficient to ensure protection during the whole oyster cultivation cycle, probably because of the fungicide activity reduction under mushroom farm conditions, and of the absence of natural antagonists in the growing substrate. Therefore, new alternative methods more durable and sustainable for both human and environmental health, have to be investigated. Biological control methods of $P$. ostreatus green mould have been scarcely studied. Nagy et al. (2012) and Mwangi et al. (2017) showed the efficacy of B. amyloliquefaciens, B. subtilis and B. licheniformis isolates against the disease. Zhang et al. (2010) observed that A. pullulans PL5 strain was active against postharvest pathogens of peach, apple and plum. Moreover, investigating the modes of action of PL5 strain, they suggested that the production of antibiotics was not involved, then they concluded that $A$. pullulans PL5 could be potentially registered as a biocontrol agent. At present, two strains of $A$. pullulans, DSM 14940 and DSM 14941, are commercialized as biopesticides for the control of strawberry, grape and tomato grey mould (Botector ${ }^{\circledR}$ ), of fruit tree fire blight (Blossom Protect ${ }^{\mathrm{TM}}$ ), and of apple fruit post-harvest diseases (Boni Protect). In previous works, Mari et al. (2012) and Di Francesco et al. $(2017,2018 \mathrm{~b})$ demonstrated that $A$. pullulans L1 and L8 strains were effective against stone fruit brown rot, kiwifruit grey mould and tomato blight. Our study showed that the same A. pullulans strains were fully compatible with $P$. ostreatus growth. Indeed, in the co-culturing assay, they did not hampered $P$. ostreatus colony growth, which was promoted by volatile and nonvolatile compounds produced by L8 strain as showed in specific assays. On the basis of these results, the effect of L1 and L8 against Trichoderma species responsible of green mold disease was studied under laboratory and growth chamber conditions. In co-culturing and volatile and nonvolatile assays, both A. pullulans strains reduced the colony growth of $T$. pleuroticola and T. pleuroti strains. In in vitro assays, the inhibitory effect of L1 and L8 was similar in the majority of the Trichoderma-A. pullulans combinations. The competition for space and nutrients and the production of volatile and nonvolatile compounds seemed to be responsible for the biocontrol activity, while hyphal interaction seemed not to be involved in the antagonistic activity of the yeast as observed also by Zhang et al. (2010) for A. pullulans PL5 strain against post-harvest pathogens. Similarly, Di Francesco et al. (2015a) showed that the same mechanisms reported above played a significant role in the antagonism of L1 and L8 strains against Monilinia laxa, causal agent of peach brown rot. The competition for space and nutrients and the absence of hyphal interaction were also showed by the A. pullulans LS-30 strain against Botrytis cinerea, Penicillium expansum, Rhizopus stolonifera and Aspergillus niger, and no antibiosis was involved in its antagonistic activity (Castoria et al. 2001). Di Francesco et al. (2015b) identified four volatile organic compounds produced by L1 and L8 strains as phenethyl alcohol, 1-butanol-3-methyl, 1-butanol-2-methyl and 1-propanol-2-methyl belonging to the group of alcohols which were active against several postharvest pathogens. $\mathrm{Au}$ reobasidium pullulans is well known also for the production of nonvolatile metabolites, such as the pullulan which has numerous applications in medicine, pharmacy, food industry and other fields (Leathers, 2003; Cheng et al., 2011), and a $\beta$-glucan consumed as health-promoting food with beneficial immunomodulatory effects (Tada et al., 2009; Muramatsu et al., 2012). To our knowledge, no data on the identification of yeast nonvolatile metabolites effective against plant pathogens are available. Considering that these compounds produced by L1 and L8 strains were effective not only against Trichoderma species pathogenic of $P$. ostreatus, but also against Phytophthora infestans responsible of tomato late blight (Di Francesco et al., 2017), their identification is ongoing, in order to verify the absence of metabolites with risk for environment and human health. Aureobasidium pullulans is a saprophytic fungus that is widely distributed in the environment, and like many saprophytic fungi, in the right host A. pullulans can be an opportunistic human pathogen (Mehta et al., 2017). Indeed, this fungus caused infections in immunocompromised or chronically ill patients (Chan et al., 2011; Mershon-Shier et al., 2011; Najafzadeh et al., 2014; Chowdhary et al., 2015; Mehta et al., 2017). It is supposed that extracellular enzymatic activities could also be involved in A. pullulans antagonistic activity towards T. pleuroti and T. pleuroticola. Castoria et al. (2001) showed that exochitinase ( $\mathrm{N}$-acetyl-b-D-glucosaminidase) and $\beta$-1-3-glucanase activities were involved in the antagonism of $A$. pullulans $\mathrm{LS}-30$ strain against several plant pathogens.

When the biocontrol activity of L1 and L8 was tested against the green mould disease caused by T. pleuroti 492 and T. pleuroticola 432, only L8 strain was effective. We highlight that the effectiveness of L8 against $T$. pleuroticola 432 disease was similar to that of prochloraz used at field dose, whereas the biocontrol effect of L8 against T. pleuroti 492 disease was lower than that showed by the fungicide. Trichoderma pleuroti 492 was more aggressive than $T$. pleuroticola 432 against $P$. ostreatus, consistently to Innocenti et al. (2019). The different aggressiveness of $T$. pleuroti 492 and T. pleuroticola 432 could justify the different biocontrol efficacy showed by L8.

Another important outcome of A. pullulans application in mushroom crop could be the improvement of $P$. ostreatus fruit-body nutraceutical properties, which are deeply influenced by the substrate cultivation 
(Carrasco-Gonzalez et al., 2017). In a previous work, the amino acid analysis of kiwifruit juice amended with L1 and L8 showed that both aspartic and glutamic acid content was increased, and that new amino acids such as serine, glycine, threonine, arginine, alanine and valine were produced (Di Francesco et al., 2018b). This aspect is now under investigation in $P$. ostreatus fruit bodies produced in a substrate amended with $A$. pullulans strains.

In conclusion, we demonstrated, for the first time, the effectiveness of A. pullulans in reducing Trichoderma colony growth in in vitro assays, and the control of green mould disease under conditions comparable to those of a mushroom farm, where only L8 strain was effective. In the case of the less aggressive Trichoderma species, the strain was even effective as the chemical. Based on the above, the patent $n$. 102018000007085 was developed by Bologna University for the application of L8 strain in $P$. ostreatus farm against the green mould disease. CRediT authorship contribution statement

Roberta Roberti: Formal analysis, Methodology, Data curation, Writing - review \& editing. Alessandra Di Francesco: Methodology. Gloria Innocenti: Conceptualization, Resources. Marta Mari: Supervision.

\section{Appendix A. Supplementary data}

Supplementary data to this article can be found online at https:// doi.org/10.1016/j.biocontrol.2019.04.016.

\section{References}

Alfonzo, A., Torta, L., Burruano, S., 2008. Specie di Trichoderma associate alla muffa verde di Pleurotus ostreatus. Micologia Italiana 3, 39-45.

Andrews, J.H., 2006. Population growth and the landscape ecology of microbes on leaf surfaces. In: Bailey, M.J., Lilley, A.K., Timms-Wilson, T.M., Spencer-Phillips, P.T.N. (Eds.), Microbial Ecology of Aerial Plant Surfaces. CABI, Wallingford, UK, p. 241.

Bellettini, M.B., Bellettini, S., Fiorda, F.A., Pedro, A.C., Bach, F., Fabela-Morón, M.F., Hoffmann-Ribani, R., 2018. Diseases and pests noxious to Pleurotus spp. mushroom crops. Rev. Argent. Microbiol. 50, 216-226.

Bencheqroun, S.K., Bajji, M., Massart, S., Labhilili, M., El Jaafari, S., Jijakli, M.H., 2007. In vitro and in situ study of postharvest apple blue mold biocontrol by Aureobasidium pullulans: evidence for the involvement of competition for nutrients. Postharvest Biol. Technol. 46, 128-135.

Chan, G.F., Puad, M.S.A., Chin, C.F., Rashid, N.A.A., 2011. Emergence of Aureobasidium pullulans as human fungal pathogen and molecular assay for future medical diagnosis. Folia Microbial. 56, 459-467.

Carrasco-Gonzalez, J.A., Serna-Saldivar, S.O., Gutiérrez-Uribe, J.A., 2017. Nutritional composition and nutraceutical properties of the Pleurotus fruiting bodies: potential use as food ingredient. J. Food Compos. Anal. 58, 69-81.

Castoria, R., De Curtis, F., Lima, G., Caputo, L., Pacifico, S., De Cicco, V., 2001. Aureobasidium pullulans (LS-30) an antagonist of postharvest pathogens of fruits: study on its modes of action. Postharvest Biol. Technol. 22, 7-17.

Cheng, K.C., Demirci, A., Catchmark, J.M., 2011. Pullulan: biosynthesis, production, and applications. Appl. Microbiol. Biotechnol. 92, 29.

Chowdhary, A., Perfect, J., de Hoog, G.S., 2015. Black molds and melanized yeasts pathogenic to humans. Cold Spring Harb. Perspect. Med. 5, a019570.

Dennis, C., Webster, J., 1971. Antagonistic properties of species-groups of Trichoderma. II Production of volatile antibiotics. Trans. Br. Mycol. Soc. 57, 41-48.

Dennis, C., Webster, J., 1971. Antagonistic properties of species-groups of Trichoderma. I Production of non-volatile antibiotics. Trans. Br. Mycol. Soc. 57, 25-39.

Di Francesco, A., Calassanzio, M., Ratti, C., Mari, M., Folchi, A., Baraldi, E., 2018. Molecular characterization of the two postharvest biological control agents Aureobasidium pullulans L1 and L8. Biol. Control 123, 53-59.

Di Francesco, A., Mari, M., Ugolini, L., Baraldi, E., 2018. Effect of Aureobasidium pullulans strains against Botrytis cinerea on kiwifruit during storage and on fruit nutritional composition. Food Microbiol. 72, 67-72.

Di Francesco, A., Milella, F., Mari, M., Roberti, R., 2017. A preliminary investigation into Aureobasidium pullulans as a potential biocontrol agent against Phytophthora infestans of tomato. Biol. Control 114, 144-149.

Di Francesco, A., Roberti, R., Martini, C., Baraldi, E., Mari, M., 2015. Activities of Aureobasidium pullulans cell filtrates against Monilinia laxa of peaches. Microbiol. Res. 181, $61-67$.

Di Francesco, A., Ugolini, L., Lazzeri, L., Mari, M., 2015. Production of volatile organic compounds by Aureobasidium pullulans as a potential mechanism of action against postharvest fruit pathogens. Biol. Control 81, 8-14.

Dimakopoulou, M., Tjamos, S.E., Antoniou, P.P., Pietri, A., Battilani, P., Avramidis, N., Markakis, E.A., Tjamos, E.C., 2008. Phyllosphere grapevine yeast Aureobasidium pullulans reduces Aspergillus carbonarius (sour rot) incidence in wine-producing vineyards in Greece. Biol. Control 46, 158-165.

Gunde-Cimerman, N., Zalar, P., de Hoog, S., Plemenitaš, A., 2000. Hypersaline waters in salterns-natural ecological niches for halophilic black yeasts. FEMS Microbiol. Ecol. $32,235-240$.
Hatvani, L., Antal, Z., Manczinger, L., Szekeres, A., Druzhinina, I.S., Kubicek, C.P., Nagy, A., Nagy, E., Vágvölgyi, C., Kredics, L., 2007. Green mould diseases of Agaricus and Pleurotus spp. are caused by related but phylogenetically different Trichoderma species. Phytopathology 97, 532-537.

Hatvani, L., Sabolic, P., Kocsube, S., Kredics, L., Czifra, D., Vágvölgyi, C., Kaliterna, J., Ivić, D., Đermić, E., Kosalec, I., 2012. The first report of mushroom green mould disease in Croatia. Arh. Hig. Rada. Toksikol. 63, 481-487.

Innocenti, G., Montanari, M., Righini, H., Roberti, R., 2019. Trichoderma species associated with green mould disease of Pleurotus ostreatus and their sensitivity to prochloraz. Plant Pathol. 68, 392-398. https://doi.org/10.1111/ppa.12953.

Ippolito, A., El Ghaouth, A., Wilson, C.L., Wisniewski, M., 2000. Control of postharvest decay of apple fruit by Aureobasidium pullulans and induction of defense responses. Postharvest Biol. Technol. 19, 265-272.

Janisiewicz, W.J., Kurtzman, C.P., Buyer, J.S., 2010. Yeasts associated with nectarines and their potential for biological control of brown rot. Yeast 27, 389-398.

Komon-Zelazowska, M., Bisset, J., Zafari, D., Hatvani, L., Manczinger, L., Woo, S., Lorito, M., Kredics, L., Kubicek, C.P., Druzhinina, I.S., 2007. Genetically closely related but phenotypically divergent Trichoderma species cause green mold disease in oyster mushroom farm worldwide. Appl. Environ. Microbiol. 73, 7415-7426.

Kredics, L., Hatvani, L., Antal, Z., Manczinger, L., Druzhinina, I.S., Kubicek, C.P., Szekeres, A., Nagy, A., Vágvölgyi, C., Nagy, E., 2006. Green mould disease of oyster mushroom in Hungary and Transylvania. Acta Microbiol. Immunol. Hung. 53, 306-307.

Leathers, T.D., 2003. Biotechnological production and applications of pullulan. Appl. Microbiol. Biotechnol. 62, 468-473.

Lima, G., Ippolito, A., Nigro, F., Salerno, M., 1997. Effectiveness of Aureobasidium pullulans and Candida oleophila against postharvest strawberry rots. Postharvest Biol. Technol. 10, 169-178.

Mari, M., Martini, C., Guidarelli, M., Neri, F., 2012. Postharvest biocontrol of Monilinia laxa, Monilinia fructicola and Monilinia fructigena on stone fruit by two Aureobasidium pullulans strains. Biol. Control 60, 132-140.

Martínez-Romero, D., Ramos, P., Santos, M., Barreiro, M.G., Ferreira-Pinto, M.M., 2012 Effect of controlled atmosphere gases $\left(\mathrm{CO}_{2}, \mathrm{O}_{2}\right.$ and ethylene) on growth and survival of Aureobasidium pullulans. Acta Hortic. 934, 387-391.

Martini, M., Musetti, R., Grisan, S., Polizzotto, R., Borselli, S., Pavan, F., Osler, R., 2009. DNA-dependent detection of the grapevine fungal endophytes Aureobasidium pullulans and Epicoccum nigrum. Plant Dis. 93, 993-998.

Mehta, S.R., Johns, S., Stark, P., Fierer, J., 2017. Successful treatment of Aureobasidium pullulans central catheter-related fungemia and septic pulmonary emboli. IDCases 10 65-67.

Mershon-Shier, K.L., Deville, J.G., Delair, S., Fothergill, A.W., Wickes, B., de Hoog, G.S. Sutton, D.A., Lewinski, M.A., 2011. Aureobasidium pullulans var. melanigenum fungemia in a pediatric patient. Med. Mycol. 49, 80-83.

Muramatsu, D., Iwai, A., Aoki, S., Uchiyama, H., Kawata, K., Nakayama, Y., Nikawa, Y. Kusano, K., Okabe, M., Miyazaki, T., 2012. $\beta$-glucan derived from Aureobasidium pullulans is effective for the prevention of influenza in mice. PloS One 7 (7), e41399https: //doi.org/10.1371/journal.pone.0041399.

Mwangi, R.W., Kariuki, S.T., Wagara, I.N., 2017. Biocontrol of Green Mould Disease of Oyster Mushroom (Pleurotus ostreatus) using Bacillus amyloliquefaciens. J. Biol Agric. Healthc. 7 (10), 25-30.

Nagy, A., Manczinger, L., Tombácz, D., Hatvani, L., Gyõrfi, J., Antal, Z., Sajben, E., Vágvölgyi, C., Kredics, L., 2012. Biological control of oyster mushroom green mould disease by antagonistic Bacillus species. Biological control of fungal and bacterial plant pathogens. IOBC-WPRS Bull. 78, 289-293.

Najafzadeh, M.J., Sutton, D.A., Keisari, M.S., Zarrinfar, H., de Hoog, G.S., Chowdhary, A., Meis, J.F., 2014. In vitro activities of eight antifungal drugs against 104 environmental and clinical isolates of Aureobasidium pullulans. Antimicrob. Agents Chemother. $58,5629-5631$

Park, M.S., Bae, K.S., Yu, S.H., 2006. The new species of Trichoderma associated with green mold of oyster mushroom cultivation in Korea. Mycobiology 34, 11-13.

Parsa, S., García-Lemos, A.M., Castillo, K., Ortiz, V., López-Lavalle, L.A.B., Braun, J., Vega, F.E., 2016. Fungal endophytes in germinated seeds of the common bean, Phaseolus vulgaris. Fungal Biol. 120, 783-790.

Pugh, G.J.F., Buckley, N.G., 1971. Aureobasidium pullulans: an endophyte in sycamore and other trees. Trans. Br. Mycol. Soc. 57, 227-231.

Samson, R.A., Hoekstra, E.S., Frisvad, J.C. (Eds.), 2004. Introduction to Food- and Airborne Fungi, 7th ed., Centraalbureau voor Schimmelcultures (CBS), Utrecht Nether lands, p. 389.

Sharma, S.R., Vijay, B., 1996. Yield loss in Pleurotus ostreatus spp. caused by Trichoderma viride. Mushroom Res. 5, 19-22.

Sobieralski, K., Siwulski, M., Kommon-Żelazowska, M., Błaszczyk, L., Sas-Golak, I., Frużyńska-Joźwiak, D., 2012. Impact of Trichoderma pleurotum and T. pleuroticola isolates on yielding of Pleurotus ostreatus (Fr.) Kumm.. J. Plant Protect. Res. 52, 165-168.

Tada, R., Tanioka, A., Ishibashi, K., Adachi, Y., Tsubaki, K., Ohno, N., 2009. Involvement of branched units at position 6 in the reactivity of a unique variety of beta-D-glucan from Aureobasidium pullulans to antibodies in human sera. Biosci. Biotechnol. Biochem. 73, 908-911.

Wachowska, U., Borowska, J., 2014. Antagonistic yeasts competes for iron with winter wheat stem base pathogens. Gesunde Pflanz. 66, 141-148.

Woo, S.L., Di Benedetto, P., Senatore, M., Abadi, K., Gigante, S., Soriente, I., Ferraioli, S, Scala, F., Lorito, M., 2004. Identification and characterization of Trichoderma species aggressive to Pleurotus in Italy. J. Zhejiang Univ. Agric. Life Sci. 30, 469-470.

Woo, S.L., Kubicek, C.P., Druzhinina, I.S., Vinale, F., Cavallo, P., Lorito, M., 2009. Characterization of Trichoderma species associated with the production of Pleurotus ostreatus in Italy. J. Plant Pathol. 91 (S4), 94.

Zalar, P., Gostinčar, C., De Hoog, G.S., Uršič, V., Sudhadham, M., Gunde-Cimerman, N., 2008. Redefinition of Aureobasidium pullulans and its varieties. Study Mycol. 61, $21-38$ 
R. Roberti et al.

Zhang, D., Spadaro, D., Garibaldi, A., Gullino, M.L., 2010. Efficacy of the antagonist Aureobasidium pullulans PL5 against postharvest pathogens of peach, apple and plum and its modes of action. Biol. Control 54, 172-180.

7 